\title{
Intersectionality as multi-level analysis: Dealing with social inequality
}

European Journal of Women's Studies I8(I) 5I-66 (C) The Author(s) 2011 Reprints and permission: sagepub.co.uk/journalsPermissions.nav DOI: $10.1177 / 1350506810386084$ ejw.sagepub.com

@SAGE

\author{
Gabriele Winker \\ Hamburg University of Technology, Germany
}

\author{
Nina Degele \\ University of Freiburg, Germany
}

\begin{abstract}
The concept of intersectionality is on its way to becoming a new paradigm in gender studies. In its current version, it denominates reciprocities between gender, race and class. However, it also allows for the integration of other socially defined categories, such as sexuality, nationality or age. On the other hand, it is widely left unclear as to which level these reciprocal effects apply: the level of social structures, the level of constructions of identity or the level of symbolic representations. This article advocates an intersectional multi-level analysis which takes into account reciprocal effects between the various levels. This approach includes an analytical grasp of and methodical reflection on these reciprocal effects as well as making them empirically accessible.
\end{abstract}

\section{Keywords}

body, class, gender, identity, inequality, intersectionality, methodology, multi-level analysis, race, representation, social structure

\section{Introduction: Intersectional challenges}

Since the 1990s, gender, queer and postcolonial studies have taken an interest in the interaction of dimensions of inequality - such as gender, class, race or sexuality. For this endeavour the term 'intersectionality' was coined: instead of merely summarizing the effects of one, two or three oppressive categories, adherents to the concept of intersectionality stress the interwoven nature of these categories and how they can mutually strengthen or weaken each other (Crenshaw, 1989). The concept of intersectionality is thus on its way to becoming a new paradigm in gender and queer studies: its comprehensive approach has the potential to look beyond the different theoretical currents and

\section{Corresponding author:}

Gabriele winker,Arbeit-Gender-Technik (M-I),TU Hamburg-Harburg, D-2 107I Hamburg, Germany.

Email:winker@tu-harburg.de 
offers up further perspectives for constructive development and utilization. However, 'feminists have written relatively little about the methodologies for studying intersectionality' (Denis, 2008: 685). This seeming lack of a methodological analysis is problematic, since researchers of diverse provenances work with this concept: 'It can be used in both quantitative or qualitative work (McCall 'Complexity'), which examines the micro level of lived experiences (Smith; Shields), the meso level of organisations (Acker) or social structures (Risman), and the macro level (McCall Complex Inequality), including internationality' (Bilge and Denis, 2010: 4).

Against this backdrop, we focus on methodological issues in discussing intersectionality. How can we realize socially relevant categories of inequality methodically and comprehend them empirically? In order to be able to undertake empirical intersectional research a methodologically grounded method is required. We want to demonstrate in this approach how the interrelatedness of categories of inequality on various levels can be grasped and analysed as a part of the empirical research process. Starting out from a multi-level approach, we consider social structures, including organizations and institutions (macro and meso level), as well as processes of identity construction (micro level) and cultural symbols (level of representation).

To make this process more concrete, in the section that follows we theorize categories of inequality on these three levels. In order to show how the interwoven nature of inequality structures on different levels can be used in empirical research as a tool to analyse social inequalities, we then suggest, following Pierre Bourdieu, a praxeological methodology. In the fourth section, using an empirical study which focuses on the idea of unemployment, we suggest eight concrete steps for an analysis and, in the final section, summarize the benefits of an intersectional approach.

\section{Categories and levels}

The current debate regarding intersectionality is above all centred on questions concerning relevant categories of inequality and differences in power. No less important, but still comparatively in the background, is the discussion regarding methodology. Following Leslie McCall (2005) and in a modified fashion Sylvia Walby (2007), we can distinguish anticategorial, intracategorial and intercategorial complexity as forms of intersectionality.

Anticategorial complexity is seen as a deconstruction of analytical categories such as gender and race, and focuses attention on the ways in which concepts, terms and categories are constructed. This approach has found a genealogical application in the fields of historical and literary sciences. Difference and not identity stand in the foreground, something that has a tendency to make group constructions and empirical research problematic. Nevertheless, this level of reflection is essential when the focus falls on the reconstruction of the meaning of terms, concepts and categories, even when they are not explicitly labelled as such.

Intracategorial complexity focuses on 'particular social groups at neglected points of intersection' (McCall, 2005: 1774). It is concerned with reconstructing intersections of single dimensions on a micro level. Case studies, ethnographic and narrative research methods are the primary focus (Harvey, 2005; Ludvig, 2006; Prins, 2006). This, 
however, can lead to the problem of an ongoing diminishment of the importance of group identification within the research. There is also the danger of a kind of "cultural reductionalism' (Walby, 2007: 451-2), as this approach can make addressing more large-scale questions using generalized criteria impossible.

Intercategorial complexity makes a strategic use of categories and analyses relations of multiple inequalities between socially constructed groups. This approach orientates itself above all towards the relationship between categories, mainly (though not entirely) in quantitative research (McCall, 2001; Walby, 2009). An example of this would be the modelling of income-indicators and income-differences between (fixed) social groups (McCall, 2001). In this method, categories which form the study criteria are selected in advance.

Each of these different approaches, then, has a differing focus. The anticategorial approach deals with the deconstruction of categories and not with empirical research, instead concerning itself with the implicit assumptions that lie behind every research method. The analysis of identity construction is primarily conducted on the micro level; the analysis of the structural positioning of large groups is above all grounded in the macro level. Taking our cue from the current focal points in this debate, we call for a multi-level intersectional approach that encompasses differentiation and inequality on the levels of representation, identity and structure. Up to now, this has not been the case.

On the contrary, many theoretical approaches and much empirical research has conceived structures, identities and representations as mutually exclusive categories, accordingly focusing on one, at most two of those levels. In such a way, Anna Bredström (2006) neglects the level of social structures and also of interactive agency which does not become apparent in language. The sociostructural approaches of Leslie McCall (2001), Sylvia Walby (2009) and Joan Acker (2006) in contrast do not consider norms and ideologies sufficiently. Barbara Risman (2004) pleads vehemently for the integration of three levels; alongside the levels of identity and structure, individual gender differences enter into her typology - promising no further insight due to their individualistic constrictiveness. At the same time, the level of symbolic representation is missing. Lynn Weber (2001) specifies systems of repression on the micro and macro levels, as well as with regard to ideological, political and economic dimensions. This takes place using the socially defined categories of race, class, gender and sexuality that are, however, insufficiently theoretically conceptualized. Patricia Hill Collins (1990) correlates the 'matrix of domination' of various groups within larger social groupings (particularly men and women) with patterns of privilege and marginalization. This matrix of domination extends to the levels of 'personal biography; the group or community level of the cultural context created by race, class, gender; and the systemic level of social institutions' (Collins, 1990: 227). With such a method, intersections can be seen as permeated through all levels; something that is, however, not further methodologically expounded on.

In light of this situation, Linda McDowell (2008), almost despairingly asks: 'Whether and how can we move beyond case studies and start deducing theoretical conclusions?' Still, with her demand for 'theoretical promiscuity' (McDowell, 2008: 504), her argument stagnates to the point where she, too, declares: 'Methodologically, I think we have to work harder to acquire and use multiple approaches' (McDowell, 2008: 504). With this in mind, intersectionality is still facing a series of open questions such as: Which 
categories should be considered? How many of them can be handled in a practical way? How can their interferences be theorized?

We suggest a multi-level approach in line with the epistemological reflections of Sandra Harding (1986) when she discusses the symbolic, structural and individual aspects of social genders. Accordingly, we understand intersectionality as a system of interactions between inequality-creating social structures (i.e. of power relations), symbolic representations and identity constructions that are context-specific, topic-orientated and inextricably linked to social praxis. The multi-level approach we suggest will be able to analyse the interactions of categories of difference on both a single level and throughout all three levels.

\section{Identity constructions}

Individuals constitute their identities in delineation from others, while at the same time creating a sense of belonging. The doing difference approach, according to which gender, class and ethnicity form and function simultaneously, refers to the interrelation of categories at the construction of identity (West and Fenstermaker, 1995). This must, however, also include processes of making categories irrelevant - in the way how, for example, Francine Deutsch (2007) has shown in 'Undoing gender'. Because of ongoing processes of individualization, it clearly makes no sense to limit the categories of gender, class and ethnicity. Consequently, an intersectionality-based approach has to always keep open the number of socially defined categories available and necessary for analysis on this level of research.

\section{Symbolic representations}

Likewise, an ideological justification against the accusation of injustice is required. Such norms, ideologies and representations, used as hegemonically verified justifications, are based on naturalizing and/or hierarchy-creating assessments on the grounds of numerous categories of difference. In contrast to the structural level, these differentiations do not have to be organized on a limited number of categories. This is due to the fact that, unlike with the designation of structural power relations, a reduction of complexity is not in focus here. That said, the level of representation is not a mere addendum for the creation and support of inequality-creating categories. Symbolic representations support, in their role as ideologies and norms of justification, structural power relations and are - at the same time - generated with them. Creating a fiction of security, norms and values enable identity constructions. In turn, these individual subjectification processes stabilize symbolic representations through performative acts.

\section{Social structures}

The task on the structural level consists of identifying concrete relations of power and then analysing their interrelatedness and changes (see Pollert, 1996; Verloo, 2006; Yuval-Davis, 2006). Thus, before thinking about their interrelations, inequality-creating phenomena must first be able to be properly described. For this reason, conceptual differentiations on a theoretical basis are required. Contrastingly, the interrelatedness of these power relations 
can be empirically, that is to say historically, observed and investigated and are not deducible in a purely theoretical way. Accordingly, we can distinguish between categories of class, gender, race and body on the sociostructural level. Out of these, we can deduce the power relations of classisms, heteronormativisms, racisms and bodyisms.

Class is derived from the social origin of a person, the cultural resource of education and profession as well as the resource of social networks and relationships (see Bourdieu, 1986). From this understanding of class, we deduce classisms, namely power relations perpetuating considerable income and wealth inequalities on the foundations of social origin, education and profession (see Weinbach, 2006: 89-101). Classisms explicitly do not relate themselves exclusively to economics and politics, but instead affect all areas of society including family, living conditions, voluntary work and, of course, housework (see also Walby, 2007: 458-61).

Gender does not only encompass a binary concept of gender, but also closely related sexual orientation: gender designates the naturalized (and therefore unquestioned) binary male-female differentiation as well as a 'common-sensical' heterosexualization in gender relations which is called heteronormativity. ${ }^{1}$ Accordingly, heteronormativisms denote power relations that are grounded in hierarchical gender relations as well as in unquestioned assumptions about naturalized heterosexuality and a binary gender order. The decisive difference to classisms lies in their basis of legitimization: here it is by recourse to a kind of naturalism, while classism legitimizes itself through performance.

Similarly to heteronormativisms, racisms are legitimized through recourse to naturalism. We see racisms as relations of power resting on a structural asymmetry of power between human groups that have been transformed symbolically into races. Race means 'human groups that, through symbolic classification, become "Races" ' (Weiß, 2001: 29; our translation). In this context, the decisive idea of the system is a designation and definition practice creating a specific knowledge about presupposed alleged natural differences between 'Us' and the 'Others'. A structural discrimination can, for example, be reflected in nationalities, ethnicities, religions or worldviews that deviate from the majority in society. Our understanding of racisms relates to all of these different criteria, and rests on the core of the differentiation between centre and periphery.

Regarding the choice of the first three categories - class, gender, race - we follow valuable lines of argumentation from intersectionality literature. Floya Anthias (2001: 368), for example, understands gender, ethnicity/race and class as oppressive structural categories, since history has shown how unequal allocations of resources (and consequently also of life chances) run alongside these three lines of difference. Organizations are the sociostructural realm of the production of inequalities, something which Acker (2006: 443) draws to the centre of her thinking: she defines such inequality regimes as 'loosely related practices, processes, actions, and meanings that result in and maintain class, gender, and racial inequalities within particular organizations'. However, one dimension is so far missing from the discussion: body. We regard body as a fourth structural category because, in the same way as cultural productivity, bodily productivity generates similar structural inequalities in capitalist societies

It is crucial for our analysis that body is perceived less and less as a fact of nature, and more a product of culture, due to the fact that it can be manipulated mechanically, genetically, mentally and physiologically. Optimizing the body is aimed at improving its employability. A physically healthy workforce is demanded, illness and physical disability have a 
negative effect on career opportunities. Bodies are supposed to be optimized in order to function better, thus following a 'performance principle' that previously was only applied to the category of class. As a result, age, bodily condition, health and attractiveness in the last decades have exerted an ever-increasing influence in relation to labour and have great impact on the sharing of resources. In accordance with the importance of the structural category body, we understand bodyism as power relations between human groups in terms of physical characteristics like age, attractiveness, generativity and physical state. There are already various terminologies for such body-related hierarchical structures: ageism, lookism, ableism or able-bodyism to denote the discrimination against people on grounds of age, external appearance or disability.

A further argument is crucial in our plea to broaden the established trio of socially defined categories, race, class and gender, with the category body: race and gender are explained with and derive their legitimacy through recourse to an alleged naturalism. This has not been the case with class for quite some time. What is more pertinent nowadays is a belief in mobility and the ideology of a possible 'rags to riches' transformation. Instead of naturalization, here the dominant legitimizations are improvement and optimization - it is exactly at this point that the now non-naturalistic category of class intersects with the category of body.

In our view, the differently labelled, analytically split systems of power relations intersect with each other; therefore we focus on their interrelatedness. Furthermore, we suggest that the interplay between these power relations underlies historical changes, and that transference of meaning can take place from one category to another. What does not change, however, is the fact that the inclusions and exclusions alongside these four categories maintain an iniquitous distribution of resources. It cannot be theoretically deduced in what way they are empirically shaped, especially since this depends on the social practice of the actors (which is the starting point of our empirical procedure). These power relations are secured through activity-oriented and structure-forming norms and ideologies that we take into account by analysing symbolic representations. Furthermore, those identity constructions that are effective create a supposed ontological certainty through reference to others and cannot function without norms and structures while at the same time influencing them.

\section{Praxeological intersectionality}

The three structural levels we are concentrating on are linked through the social practices of individuals. Through social practices like social action and speech, individuals delineate themselves in social contexts, construct identities, process symbolic representations, support social structures or challenge them. Conversely, the three aforementioned levels construct a framework for social practice. Thus, social practices are intrinsically linked to each other through categories of difference and those three levels. For this reason it is social practices that serve as the methodological starting point of our intersectional multi-level analysis.

Following Pierre Bourdieu's 'Theory of Practice', we assume the starting point and subject for analysis should be social practices that are accessible through empirical research. Bourdieu makes a plea for a theory of practice that resolves the sharp division between 
empiricism and theory (Bourdieu, 1998: 82-108). This approach reveals a very important insight for the theory of intersectionality: some things cannot be classified; theoretical categories do not necessarily comply with empirical categories. This results in the need for empirical analysis not to start out with theoretical concepts but instead to begin with social practices. Regarding our approach, this means keeping the interrelation of class, gender, race and body relations firmly in our sights (while not allowing them to distract us) and beginning with our analysis in the everyday life of people. Starting out from the social practices of a person, we are able to reconstruct identities they construct, as well as the structures and norms they draw on: in the process of subjectivization, which categories do social actors relate to? Which norms, principles and interpretive patterns affect them? What are the structural contexts their agency is embedded in? Those are the questions that can be posed in order to correlate the three levels of research with each other, without losing sight of the interrelation between the various categories of difference.

Moreover, we have a method for making the unnamed, unquestioned nature of naturalized identities and power structures visible - something which has not yet been theorized in the anticategorial or intracategorial approaches: in order to be able to reach the goal of a both theory-guided and explorative social research method, we ask for it to remain both 'open to the unexpected' and an adherent to theoretical guidelines at the same time. More precisely, by this we mean a combination of inductive and deductive methods: any research has to be open to surprises, as any category could be relevant or not - but it also has to be able to detect relevancies and correlations. The combination of a limited number of structural categories with an unlimited number of identity and representation categories reconstitutes itself as an interplay of deductive (theory-led) and inductive (open to surprise) procedural methods. Theory-led processes enable us to identify unnamed (because they are taken for granted and therefore remain undiscussed) positions, which rank highly in hierarchy categories, such as 'male', 'heterosexual', 'non-disabled' or 'white'. In this way we are able to circumnavigate a basic problem which intracatagorical narrative approaches have to battle with. For example, Alice Ludwig (2006) in her intersectional analysis of the biographical narrative of a female migrant in Vienna, declared that 'the weaknesses of intersectionality becomes more obvious when trying to apply it to empirical analysis: its implications for empirical analysis are, on the one hand, a seemingly insurmountable complexity and on the other, a fixed notion of difference.... Subjectively, it is often not possible for a woman to decide whether she has been discriminated against just because of her gender or for another reason such as a foreign accent' (Ludvig, 2006: 246). This goes not only for the interviewee but also for the researcher. Which categories are relevant? What does the 'not said ${ }^{2}$ mean?

We suggest a strategy of fluctuation and comparison between deductive structural categories, on the one hand, and inductive open categories on the levels of identity construction and representation, on the other, since further categories of difference can arise on the levels of representation and identity which have to be considered for analysis. In addition, we compare series of interviews and analyse what is missing/absent. We can ascertain through the comparison of these interviews which dimensions remain omitted and attempt to relate them to typical constellations of relationships (see step 5 in the following section). 
It is due to processes at the centre of our research that we have chosen to focus on connections (between theory and empiricism, deduction and induction), as it is the social actors themselves who continuously construct and reproduce social structures (Giddens, 1984). The level of representation in the form of symbolically coded norms and ideologies lies across from constructs of identity (on the micro level) and social structures (on the macro and meso level) and rarely appears as an independent level in analyses of inequality which focus on social structure. In contrast, we deem it important to be able to identify symbolic representations and their sphere of influence, with or without dependency on their social carrier. This is because symbolic representations also create structures and relations of power (like classisms, heteronormativisms, racisms and bodyisms) in the form of the interpellation of advertising messages, laws and the mass media. In this way, the social order gradually settles itself permanently into the heads of the people (it becomes unconscious), and social distinctions become invisible. Thus, the identityconstructs of actors and their representations are connected with each other through their performativity and subsequently generate structures. Structures generated in this way can only be active in their execution. Identities and representations are therefore factors which create and maintain structures as well. How does this work in detail?

\section{Intersectional analysis in eight steps}

The following suggested eight steps serve to facilitate the analysis of the empirical material. In the context of an intersectional analysis, all of these steps are required. Their order is not prescriptive and the steps can be repeated again and again. Our study concerned itself with the everyday coping strategies of unemployed people. Thirteen narrative interviews were carried out with people with no paid employment. They were differentiated in terms of age, social origin, gender, sexual orientation, child responsibility, nationality ethnicity, work experience, physical capability and so on. The main focus of the interview process was not to preempt categories of difference in order to avoid any reification of them (Winker and Degele, 2009: 99-140). We begin with formally describing what we did in our study and then go on to present some conclusions.

\section{Step I: Describing identity constructions}

When people speak about themselves in order to clarify to others who they are, they do so with reference to categories of differentiation: 'This entails the radically disturbing recognition that it is only through the relation to the Other, the relation to what it is not, to precisely what it lacks, to what has been called its constitutive outside that the "positive" meaning of any term - and thus its "identity" - can be constructed' (Hall, 1996: 4ff.). Simply put: we know who we are when we know from whom we delineate ourselves. This is true even when the 'Other' is not even referenced; delineation can also be implicit. Therefore, the first step of an intersectional multi-level analysis is to identify all discoverable categories of differentiation that serve as 'self-positioners' in an interview, a participatory observation, a group discussion or any other research method (in short: that constitutes a social practice). This approach corresponds to the intracategorical complexity shown earlier whereby relevant/pertinent intersections are searched for within a biography, history or story. That also applies to implicit (because they are self-evident 
and hence non-thematized) positions such as 'male', 'heterosexual' or 'white'. In one interview, for example, it became clear that one person defined themselves above all in relation to men (in terms of their difficulty in controlling use of alcohol and their relationship to a mother-figure based only on legally determined visits or foster care). Their homelessness, nationality or whiteness is, in contrast, not so problematical - for various reasons. From this we can already deduce our first intersectional findings (findings that would otherwise have been lost had the focus been only on a single category).

\section{Step 2: Identifying symbolic representations}

'Identities are therefore constituted within, not outside representation' (Hall, 1996: 4). For this reason the analysis of social practice does not only make identity-constructions reconstructible, but also the norms and values that operate within a society. These can be hegemonic representations, but also norms and values that create opposing public sociopolitical movements. This second step has the aim of making all norms, values and ideologies to which persons refer, explicit. In such a way the homeless, alcohol-dependent mother above, without any formal work training but with a varied job experience speaks comparatively less explicitly about societal expectations or perceived disdain from the 'outside world'. She doesn't make any demands on the state or expect any help from others. In an almost classic neoliberal sense, she embodies the maxim that 'you make your own luck'. At the same time she has to defend herself (the moment she recognizes she has been labelled as 'alcohol-dependent' or as a 'woman') against the idea that she cannot provide for herself or her children and that they are 'social freeloaders' who scrounge money from the state.

\section{Step 3: Finding references to social structures}

Social practices and the identity constructions linked with them (thus, the micro level) are influenced by social structures and institutions (macro and meso level). However, social practices also refer to social structures (within which people act and that they (re) produce). These references (agreeing, denying, inconclusive, indifferent) to social structures, thus to institutions, organizations or laws, have to be discovered. The resulting references are then allocated by us to the four aforementioned categories - class, gender, race, body (body denotes the crucial point of contestation of the person mentioned) deductively predetermined on the level of structure. We examine inductively if and how the interviewees, in their narratives about their everyday social practices, relate to these four structural power relations - be it directly or indirectly.

\section{Step 4: Denominating interrelations of central categories on three levels}

In this step we gather together those categories from the multitude of categories of differentiation that are important to the interviewee, starting with the level of identity. It is an indicator of a self-construction of high significance if categories of differentiation, through which persons create identities, appear additionally on the levels of representation and structure. Thus, it is crucial to uncover the most important subject constructions (that can also cut across levels) and their interwoven-ness and conflicts. In our presented 
case it is the physical dependence on alcohol that leads to conflict with the norm 'individual responsibility'. An iterative procedure is advised here, in which the first results are continuously compared to the other levels respectively, hence widening the analysis.

These four steps conclude the first part of the intersectional multi-level analysis. The focus was on the interaction of identity constructions, symbolic representations and social structures in one single case. The following section proceeds with the analysis by compiling all interviews or all social practices that were found during our research.

\section{Step 5: Comparing and clustering of subject constructions}

Step 5 is the start of the synopsis of a number of analysed interviews or group discussions. For this purpose it is advisable to divide the areas of subject matter to be researched 'on the basis of one or more features into groups or types' (Kelle and Kluge, 1999: 77-8; our translation). The types that are generated in this way resemble each other more than others in terms of particular features, so their similarity with each other must be explained with a plausible parameter value. Thus, the groups or types, on the one hand, must exhibit the greatest possible internal homogeneity and, on the other hand, be characterized by a sufficient level of external heterogeneity when compared to each other. Here we follow McCall's (2005: 1774) suggestion regarding the provisional adoption and strategic use of categories: analytical detachment and accurate description are required, however the phenomena being researched should not be essentialized. In this regard it is important not to predetermine the dimensions of comparison beforehand, that is, to explicitly not demarcate a priori the subject constructions, for example, of men from those of women. Comparative dimensions are, rather, the different social practices researched. Afterwards it can be examined reasonably if those categories of differentiation that are not used as dimensions of comparison - like gender or ethnicity - cumulate in the different types. That means: only after the types have been established do we start analysing to what extent they are gendered, ethnicized, etc.

In such a way we were able to differentiate four different groups of unemployed interviewees which we then assigned to the following clearly defined and delineated central themes.

I. Control over the bodily self. For a drug-dependent prostitute, an alcohol-dependent mother of two as well as a volunteer adviser with a background in psychiatry, it is the fear and experience of the societal control of their bodies and accompanying vulnerability that stand in the foreground of their coming to terms with unemployment.

2. Overcoming of bureaucratic barriers. For three migrants, each with a high responsibility regarding the care of their children, the primary concern is coming to terms with the mundane bureaucracy of their everyday lives. They have to make sure they receive social security money and services to ensure financial security for their families. That similarly goes for a financially insecure student from Mali whose family still live in that country. 
3. Desire for a stake in society. For an asylum applicant, an ethnic German immigrant as well as a migrant with a work permit, the focal point of their everyday lives is finding gainful employment in order to gain entitlement to cultural and social rights of the society in which they live. In this group the (role) model of a gainfully-employed person who can take care of themselves and their families is most clearly expressed. It is probably no accident that this desire is mostly of concern to men.

4. The search for financial security. Two people do not feel unemployed because they are content with their artistic and political activities. They have no gainful employment and call into question society's concentration on the idea of paid work. What they are missing is not paid employment but instead the financing of their current activities undertaken for the benefit of society.

\section{Step 6: Supplementing structural data and analysing power relations}

In step 6 we draw on further data sources on the structural level for the analysis. This is because interviewees often mention framework requirements, but subsequently do not go deeper into the subject or depict them wrongly. However, in order to understand the fear of deportation the persons in group 2 felt, a few details about degrading asylum laws and their excrescent bureaucracy were not sufficient. In this case, we had to familiarize ourselves with the structural power relations concerned. The advantage of the abovedescribed method lies in the fact that not all classisms, heteronomativisms, racisms or bodyisms that possibly affect social practice are in focus at the same time. Instead, only those facets of power relations delineated by the interviewee in concrete social practice or implicitly referred to through descriptions of the person's environment are included. We can also incorporate the 'non-naming' of categories if an interviewee benefits from particular power relations in terms of comparisons. Proceeding in such a way, we are able to counter the qualified criticism against structural analyses; that they impose structural power relations on actors, hence not doing justice to them or their experiences.

\section{Step 7: Deepening the analysis of denominated representations}

A number of statements in interviews are related to symbolic representations, that is, to the norms and values that social actors have to deal with. The next step serves to come to understand these ideologies prevailing in certain contexts by consulting additional data sources such as mass media, advertising, photographic and written documents (see step 2). This will explain which societal contexts are meaningful for these norms and values and those that sustain them. In our research it is the legally reinforced image of the 'social freeloader' and the norm of the 'performance principle' which confronts the interviewees with the supposed guilt they should feel about their social situation. These different characteristics make it clear that the concept of the 'social freeloader', in its many facets, operating as a 'flipside' to the idea of the performance principle, is a hard one to break down and that it permeates all groups with otherwise completely different social circumstances and identity constructions. 
After completing the evaluation and classification of additional sources on the level of structure in step 6 and on the level of representation in step 7, we can now begin with the final, eighth step, the elaboration of the numerous interactions that go beyond a singular case.

\section{Step 8: Elaborating interrelations in the overall demonstration}

In this final step we now, on the one hand, want to look at the interrelations and different emphases of dimensions of inequality and power relations. On the other hand, we carry this out with a view towards their modes of functioning on the three different levels. The goal is a generalization beyond the single case and type. On the structural level, we begin with the question of which classisms, heteronormativisms, racisms and bodyisms are recognizable in the field and how they are interwoven with each other. Afterwards, we examine their effects at the level of identity. In the next stage, we ask in what way the identified constructions of identity support or relativize structures. Both of these research steps show if and how individuals (or the abstracted types) are affected by the four structures of power relations. We go through a similar approach in that we take contextualized symbolic representations as our starting point. What effects do these norms have on constructions of identity in the context examined by us? What typical self-images point to the effectiveness of certain representations? Vice versa, we ask how constructions of identity stabilize or put in question established norms and values. Finally, we analyse the relationship between structural systems of power relations and symbolic representations. Here too, we examine the interrelations in two directions. Starting out from structures, first we ask where and how structural facts affect norms and ideologies and how symbolic representations depict themselves accordingly. Vice versa, we analyse if and how the named norms and values affect the structural level and how they change structural power relations. Ideally we can reach conclusions as to how far structures and representations stabilize each other or if shifts occur from the structural level to the representational level, or vice versa.

Due to their status as unemployed, all interviewees stand (within the set of wagedependent norms regarding employment) at the lowest level of the class system - behind the so-called normally employed and those in precarious occupations. That said, this position effects them in very different ways.

The fourth group of non-gainfully employed do not feel unemployed as they nevertheless take an active participation in society regardless of whether it is a wage-based occupation. They oppose the discriminatory capitalistic norm that active participation in society outside the wage economy is not financially rewarded and instead that following this norm merely leads to subjugation under the market logic of selling one's labour in exchange for a subsistence wage.

In contrast, we find in the third group that the biggest problems arise because of their marginalization and due to their position in the class system that their non-gainfully employed status creates. They expect that a wage-based occupation offers extensive access to and participation in mainstream society that is otherwise structurally (due to asylum status, work permits, residence permits) denied them. Here the intersection of a discriminatory class system and a racist system of marginalization and exclusion of migrants can clearly be seen. They place themselves in opposition to the mainstream picture of them as lacking the required engagement to find a job. They take the demand 
that they should show more initiative seriously, while also asking themselves what more they possibly should do and learn in order to increase their employability.

For the other two groups their marginalization within the class system is even more tightly linked to other power relations. The first group is marginalized and discriminated

\section{Part I: Evaluation of individual interviews}

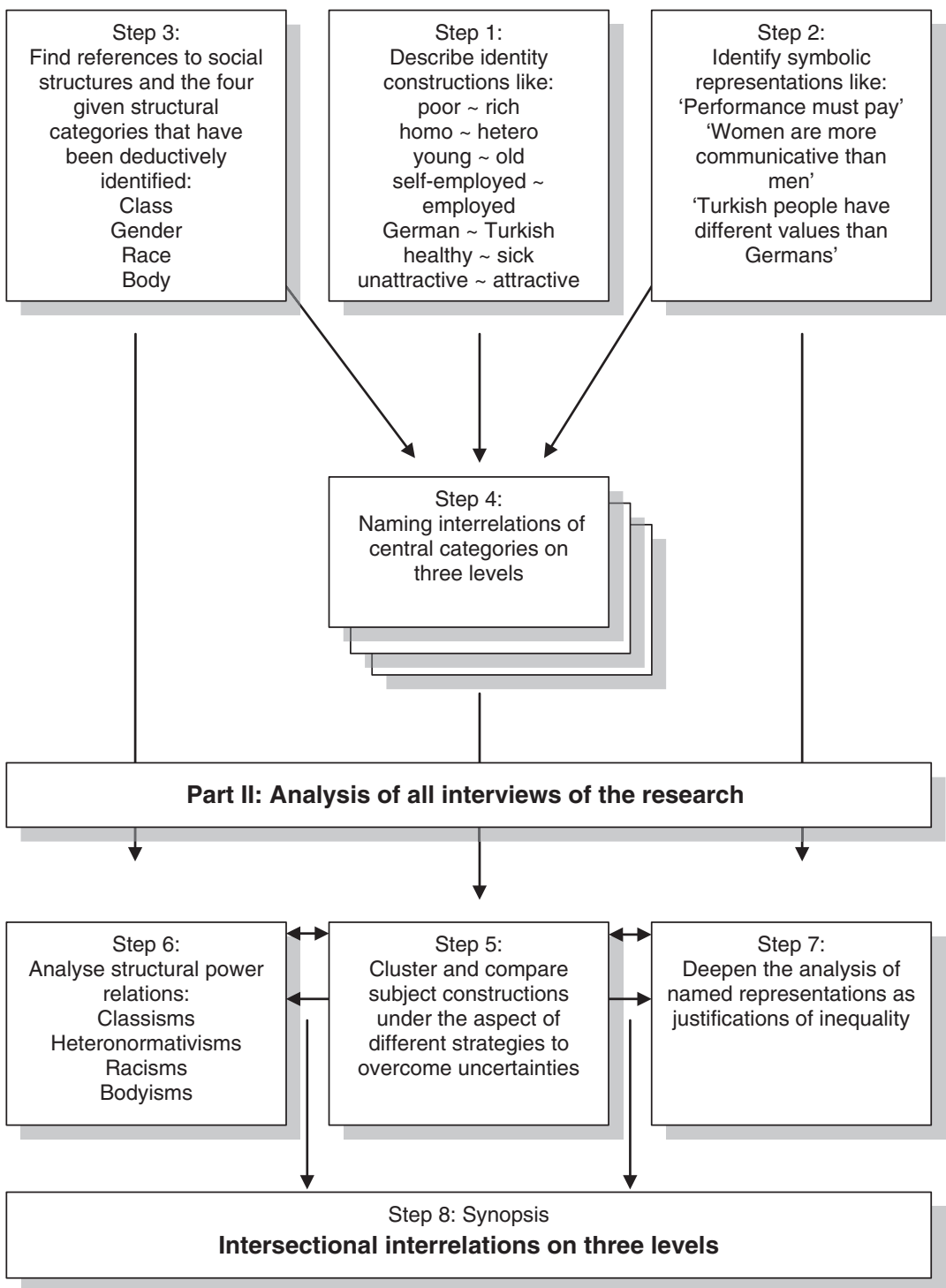

Figure I. A model of intersectional multi-level analysis 
against through the dominant idea of a perfect 'working' body. Their priority in the everyday fight for an adequate life is the search for recognition as human beings with their respective bodily limitations and dependencies. In the second group, there is a convergence between discrimination (as they are not in gainful employment) and the huge demand of overcoming enormous amounts of bureaucracy in order to gain social security payments for themselves and their children. In particular, a migrant mother has to confront pervasive accusations and images portraying her as a 'social freeloader', whose motivation for coming to Germany with her children is to profit from the state social security system. Here, class, race and body-relations converge.

Figure 1 graphically visualizes our approach.

\section{Summary}

The benefit of our approach is the access through the interactions of categories and levels, without thinking of the categories as interchangeable. This is because, first, the naming of each single chosen research level forces a preciseness that could not be reached with an unreflected change between the levels. Second, through keeping the categories on the levels of identity and representation open, reductions can be avoided, while still being able to clearly name power relations through the definition of the four categories on the structural level. With this we can link until now isolated scientific knowledge and theories to each other. Third, our proposed method facilitates a systematic approach that takes identity constructions as its starting point, but does not stop on this level.

\section{Funding}

This research received no specific grant from any funding agency in the public, commercial, or not-for-profit sectors.

\section{Notes}

1. Due to our definition of the structural construction of gender through heteronormative gender relations, sexuality is not a separate fourth category on the structural level as for example in Weber (2001) and Verloo (2006).

2. Furthermore, Sirma Bilge accuses both liberal universal feminism and postcolonial critiques in her study of the agency of veiled Muslim women of not looking for anything beyond race, class or gender to explain the wearing of the veil. 'While both currents intend to speak of women whether generic "women" or "racialised/subaltern" ones - both fail to address the reasons most frequently given by veiled women; questions of piety, morality, modesty, virtue and divinity' (Bilge, 2010: 14).

\section{References}

Acker J (2006) Inequality regimes: Gender, class, and race in organizations. Gender and Society 20(4): 441-464.

Anthias F (2001) The material and the symbolic in theorizing social stratification: Issues of gender, ethnicity and class. British Journal of Sociology 52(3): 367-390. 
Bilge S (2010) Beyond subordination vs. resistance: An intersectional approach to the agency of veiled Muslim women. Journal of Intercultural Studies 31(1): 9-28.

Bilge S and Denis A (2010) Introduction: Women, intersectionality and diasporas. Journal of Intercultural Studies 31(1): 1-8.

Bourdieu P (1986) The forms of capital. In: Richardson JG (ed.) Handbook of Theory and Research for the Sociology of Education. New York: Greenwood Press, 241-258.

Bourdieu P (1998) Practical Reason: On the Theory of Action. Stanford, CA: Stanford University Press.

Bredström A (2006) A challenge for feminist HIV/AIDS research. European Journal of Women's Studies 13(3): 229-243.

Collins PH (1990) Black Feminist Thought: Knowledge, Consciousness and the Politics of Empowerment. New York and London: Routledge.

Crenshaw K (1989) Demarginalizing the intersection of race and sex: A black feminist critique of antidiscrimination doctrine. The University of Chicago Legal Forum: 139-167.

Denis A (2008) Intersectional analysis: A contribution of feminism to sociology. International Sociology 23(5): 677-694.

Deutsch FM (2007) Undoing gender. Gender and Society 21(1): 106-127.

Giddens A (1984) The Constitution of Society: Outline of the Theory of Structuration. Cambridge: Polity Press.

Hall S (1996) Who needs 'identity'? In: Hall S and Du Gay P (eds) Questions of Cultural Identity. London: Sage, 1-17.

Harding S (1986) The Science Question in Feminism. Ithaca, NY: Cornell University Press.

Harvey AM (2005) Becoming entrepreneurs: Intersections of race, class, and gender at the black beauty salon. Gender and Society 19(6): 789-808.

Kelle U and Kluge S (1999) Vom Einzelfall zum Typus [From Single Case to Type]. Opladen: Leske und Budrich.

Ludvig A (2006) Intersecting voices in a female narrative. European Journal of Women's Studies 13(3): 245-258.

McCall L (2001) Complex Inequality: Gender, Class, and Race in the New Economy. New York: Routledge.

McCall L (2005) The complexity of intersectionality. Signs. Journal of Women in Culture and Society 30(3): 1771-1800.

McDowell L (2008) Thinking through work: Complex inequalities, constructions of difference and trans-national migrants. Progress in Human Geography 32(4): 491-507.

Pollert A (1996) Gender and class revisited; or, the poverty of 'patriarchy'. Sociology 30(4): 639659.

Prins B (2006) Narrative accounts of origins: A blind spot of the intersectional approach. European Journal of Women's Studies 13(3): 277-290.

Risman BJ (2004) Gender as a social structure: Theory wrestling with activism. Gender and Society 18(4): 429-450.

Verloo M (2006) Multiple inequalities, intersectionality and the European Union. European Journal of Women's Studies 13(3): 211-228.

Walby S (2007) Complexity theory, systems theory, and multiple intersecting social inequalities. Philosophy of the Social Sciences 37(4): 449-470. 
Walby S (2009) Globalization and Inequalities: Complexity and Contested Modernities. London: Sage.

Weber L (2001) Understanding Race, Class, Gender, and Sexuality: A Conceptual Framework. New York: McGraw-Hill.

Weinbach H (2006) Social Justice statt Kultur der Kälte. Alternativen zur Diskriminierungspolitik in der Bundesrepublik Deutschland [Social Justice instead of Cultural Coldness: Alternatives to Discriminating Policies in the Federal Republic of Germany]. Berlin: Karl Dietz Verlag.

Weiß A (2001) Rassismus wider Willen. Ein anderer Blick auf eine Struktur sozialer Ungleichheit [Racism against its Will: A Different Look at a Structure of Social Inequality]. Wiesbaden: Westdeutscher Verlag.

West C and Fenstermaker S (1995) Doing difference. Gender and Society 9(1): 8-37.

Winker G and Degele N (2009) Intersektionalität. Zur Analyse sozialer Ungleichheiten [Intersectionality: Dealing with Social Inequality]. Bielefeld: Transcript.

Yuval-Davis N (2006) Intersectionality and feminist politics. European Journal of Women's Studies 13(3): 193-209. 